plan for what to do when ageing firefighter fails to pass the cut-off values of the tests.

Discussion The FireFit method seems to act as a tool of cooperation between OHP and actors in RRS. It seems to make early interventions more appropriate for firefighters with decreasing work ability. High quality use of the method requires continuous education and training of its users.

\section{0b PREVENTIVE INTERVENTIONS TO ASSIST WORKERS TO STAY AT WORK: WORKERS' HEALTH SURVEILLANCE (WHS) AS EXAMPLE}

1,2Judith K Sluiter*. 'Academic Medical Centre, Coronel Institute of Occupational Health, Amsterdam, The Netherlands; ${ }^{2}$ Amsterdam Public Health research institute, Amsterdam, The Netherlands

\subsection{6/oemed-2018-ICOHabstracts.95}

Introduction WHS is a preventive periodical strategy to monitor the work-relevant aspects of health in specific groups of workers. The idea is that occupational health professionals could signal individual problems that could lead to a decrease in work ability, and intervene timely on those aspects. In the Netherlands, specific guidelines exist for occupational physicians on this topic. Examples will be provided to give more insight in the relevance and effects of this strategy.

Methods For four specific jobs (doctors, nurses, construction workers, ambulance workers), job-specific WHS was developed and implemented in research and/or practice. The prevalence of signalled problems and workers' experiences with the WHS were researched, calculated and will be reported upon in detail.

Result The WHS for hospital doctors was developed, feasibility was tested and the doctors were satisfied with the process, would participate again and had the impression the WHS could improve their future work ability. In nurses, two strategies of WHS were studied in an RCT and effects on workfunctioning was tested: the WHS performed by occupational physicians was cost-effective on work-functioning compared to an e-WHS. In construction workers, a controlled study compared a job-specific WHS with the classic form and it was shown that workers more often undertook action or sought for specific after the job-specific WHS. The WHS for ambulance workers was implemented on a national level and high prevalence of job-specific health problems were found.

Discussion The positive and negative experiences with job-specific WHS as preventive strategy will be shown.

\section{C EFFECTS OF A BEHAVIOURAL INTERVENTION PROGRAM ON PERCEIVED WORK ABILITY AMONG MUNICIPAL EMPLOYEES}

\footnotetext{
${ }^{1,2} \mathrm{~B}$ Ojala, ${ }^{1} \mathrm{C}-\mathrm{H}$ Nygård*, ${ }^{1} \mathrm{H}$ Huhtala, ${ }^{1,2} \mathrm{ST}$ Nikkari. 'University of Tampere, Tampere, Finland; ${ }^{2}$ Tullinkulma Occupational Health, Tampere, Finland
}

\subsection{6/oemed-2018-ICOHabstracts.96}

Introduction Long-term sickness absence and early retirement are large problems in the municipal employment sector. Ways to support work ability and coping at work are therefore required. It is important that timely actions are targeted towards employees at risk to improve their health, promote work ability and prevent long-term sickness absence and early retirement. The aim was to evaluate effects of a cognitive behavioural therapy in an early rehabilitation program to improve employees' work ability.

Methods Participants (mean age 49,9 years) in the intervention and in the control group were measured at base-line and after a 9 month follow-up to estimate the causal impact of the intervention in the study group $(n=389)$, compared with a control group $(n=100)$ that was not offered this intervention. The work ability of both groups was measured using the work ability index (WAI). Differences were analysed within and between groups with the analysis of variance for repeated measurements

Results Participants in the intervention group showed a significant increase in several WAI areas, resulting in an overall increase in the total WAI score $(36,9-38,2 ; \mathrm{p}<0.001)$ although there was a significant decrease in WAI in the control group $(37,6-36,7 ; \mathrm{p}<0.05)$.

Conclusions The results suggest that the early rehabilitation program was effective in increasing employees' work ability, as measured by the WAI.

\section{$1620 \mathrm{~d}$ WORKSITE HEALTH PROMOTION PROGRAMS FOR AGEING WORKFORCE IN EUROPE. THE EXPERIENCE OF PROHEALTH65+}

N Magnavita, I Capitanelli. Institute of Public Health, Università Cattolica del Sacro Cuore, Rome, Italy

\subsection{6/oemed-2018-ICOHabstracts.97}

Introduction The proportion of older workers has increased substantially in European countries. The study project ProHealth65+, funded by EU-CHAFEA, collected experiences of workplace health promotion for older workers (WHPOW) conducted in 10 representative countries of Central

Europe, Eastern Europe and the Mediterranean.

Methods Research studies of WHPOW conducted from 2000, 1 st January, to 2015, 31 December, were identified through a comprehensive literature review and a search on the website of the major

European Agencies on worker health promotion. Researchers and companies were asked for additional documentation about WHPOW programmes in a survey conducted with Survey Monkey. Results A total of 622 intervention studies performed or promoted in the workplace and targeted at older workers or at the ageing of the workforce were identified. Most of the programs were carried out in Central Europe (295, 47.4\%), less in East Europe (193, $31.0 \%)$ and in Mediterranean countries (134, 21.6\%).

Discussion Our study shows that there are only a limited number of WHPOW actions throughout the 10 selected European Countries. While in Central Europe widespread interest in issues of ageing workforce has resulted in national policies to encourage WHPOW, not all the countries of Eastern Europe are equally well equipped. Lastly, in Southern Europe health promotion activities are largely inadequate compared to needs.

\section{AGEING AND MUSCULOSKELETAL DISORDERS - THE IDENTIFICATION OF MUSCULOSKELETAL RISK FACTORS AND THE WORK ABILITY INDEX}

P Rothmore* , J Gray. The University of Adelaide, Faculty of Health Sciences, School of Public Health South Australia, Australia

10.1136/oemed-2018-ICOHabstracts.98 